\title{
Pitfalls in Assessing the Depth of Invasion in Colorectal Neoplasia
}

\section{Sung Pil Hong}

Division of Gastroenterology, Yonsei University, 50 Yonsei-ro, Seodaemun-gu, Seoul, South Korea

Endoscopic removal of colorectal neoplasm is a safe and an effective treatment in reducing colorectal cancer (CRC) related incidence and mortality $[1,2]$. Recent progress in endoscopic techniques such as endoscopic mucosal resection (EMR) and endoscopic submucosal dissection (ESD) have enable endoscopists to expand these treatments to early colorectal cancers $[3,4]$. At present, colorectal neoplasms either confined to the mucosa or superficial submucosal (SM) invasion less than $1000 \mu \mathrm{m}$ are indicated for endoscopic treatment. Deep SM cancer over $1000 \mu \mathrm{m}$ invasionis not indicated for endoscopic treatment due to the high risk of lymph node metastasis with 6.9 $22.2 \%[5,6]$. Therefore, the preciseassessment of the depth of invasion in colorectal neoplasms is crucial to decide an accurate therapeutic option. Recently, Utsumi et al. proposed three-step strategy for management of colorectal neoplasia[7]. The authors suggested sequential examinations of white lightcolonoscope, narrow band imaging (NBI), and magnifying chromoendoscopy (MCE) to define deep SM cancers for surgery.

Even though recent development of hardware, we should keep in mind that the first step is morphological examination using white light colonoscope. In this point of view, size is one of the most important indicators. A previous study reported that $7.4-14 \%$ of colorectal polyps larger than $20 \mathrm{~mm}$ contained SM carcinoma and the incidence of invasive SM carcinomas increased in proportion to the tumor size $[8,9]$. Other morphological features, such as loss of lobulation, excavation, demarcated depressed areas, stalk swelling, fullness, fold convergence, and bleeding ulcers are strongly suggestive to deep SM cancer $[10,11]$. Thus, endoscopists should carefully examine polyps larger than $20 \mathrm{~mm}$ to avoid unnecessary endoscopic treatment. Recent our study showed that experienced endoscopist could predict deep SM cancer with $92.9 \%$ of a diagnostic accuracy in flat and sessile colorectal neoplasia larger than $20 \mathrm{~mm}$ using white light and high definition colonoscope [10]. However, although polyps less than $20 \mathrm{~mm}$ have only $0.07-5.80 \%$ of submucosal carcinoma [5], morphological assessment is much harder in small polyps than large polyps. Our study showed that endoscopists could detect deep SM cancer with only $71 \%$ of a diagnostic accuracy using invasive morphological features in polyps less than $20 \mathrm{~mm}$ [11]. Thus, $68 \%$ of patients with deep SM cancer of small polyps were initially undertreated. Because adenomas or superficial SM cancers are readily lifted by SM injection, non-lifting sign is another indicator for deep SM cancer. A previous study showed that the accuracy of non-lifting signs for deep SM cancers was 94.8\% [12]. However, in small polyps, the diagnostic accuracy of non-lifting sign falls to 75\% [11]. Therefore, although the prevalence of SM cancer is very low in small polyps, further diagnostic strategy is mandatory to avoid unnecessary cost and complications according to inappropriate endoscopic treatment.

Magnifying NBI is an endoscopic imaging technique that emphasizes superficial mucosal microvascular architecture [13,14] There have been several endoscopic classification systems for the assessment of depth of invasion with NBI. In the Hiroshima classification, over $95 \%$ of type C3 lesions are deep SM cancers with $100 \%$ of specificity [13]. In the Sano's classification, the accuracy, sensitivity, and specificity of capillary pattern type IIIB for deep SM cancer are $87.7 \%, 84.8 \%$, and $88.7 \%$, respectively [15]. Without magnification, NBI International Colorectal Endoscopic

\section{Publication History:}

Received: January 24, 2016

Accepted: April 09, 2016

Published: April 11, 2016

\section{Keywords:}

\section{Colorectal cance, Endoscopic removal, Colorectal Neoplasia}

(NICE) classification can be applied and one of three criteria (color, vessels, surface pattern) of deep SM cancer showed the sensitivity of $94.9 \%$ and the negative predictive value of $95.9 \%$ [16]. Because the diagnostic accuracy of NBI is generally lower than MCE, the polyps should be examined using MCE when SM cancer is suspected in NBI. MCE is an endoscopic technique that observes the microarchitecture of pits, epithelial crests or ridges at the surface of the colonic mucosa [5]. Kudo's classification of type $\mathrm{V}$ pit pattern is usually considered to be invasive SM and type VN is strongly suggestive of deep SM cancer with accuracy $98.8 \%$, sensitivity $85.6 \%$, specificity $99.4 \%[17,18]$.

It is definite that magnifying NBI or MCE significantly increases the diagnostic accuracy for assessing SM cancer. However, our recent study showed that there was only subtle increase in diagnostic accuracy from $92.9 \%$ to $95.3 \%$ when morphological evaluation was combined with NBI or MCE in polyps larger than $20 \mathrm{~mm}$ [10]. This discrepancy in especially large flat and sessile tumors is due to a focal deep SM invasion with a main superficial lesion. Thus, the focal deep SM invasion could be easily hidden by tumor. Therefore, experience and careful examination for whole lesion should be carried out to exclude a focal deep SM lesion in large colorectal neoplasia.

Precise and careful examination of polyps is the first step to decide a proper treatment. If the polyp is suspicious to SM cancer, NBI and MCE are definitely helpful to further define the depth of invasion. Especially, even though low prevalence of SM cancer, endoscopist should be familiar with the invasive morpholocial features in small polyps. With these efforts, we can reduce unnecessary cost and complications of endoscopic treatment.

\section{References}

1. Winawer SJ, Zauber AG, Ho MN, O'Brien MJ, Gottlieb LS, et al. (1993) Prevention of colorectal cancer by colonoscopic polypectomy. The National Polyp Study Workgroup. N Engl J Med 329: 1977-1981.

2. Zauber AG, Winawer SJ, O'Brien MJ, Lansdorp-Vogelaar I, van Ballegooijen $\mathrm{M}$, et al. (2012) Colonoscopic polypectomy and long-term prevention of colorectal-cancer deaths. N Engl J Med 366: 687-696.

"Corresponding Author: Dr. Sung Pil Hong, Division of Gastroenterology, Yonsei University, 50 Yonsei-ro, Seodaemun-gu, Seoul, South Korea; E-mail: SPHONG@yuhs.ac

Citation: Hong SP (2016) Pitfalls in Assessing the Depth of Invasion in Colorectal Neoplasia. Int J Gastroenterol Disord Ther 3: 123. doi: http://dx.doi. org/10.15344/2393-8498/2016/123

Copyright: () 2016 Hong. This is an open-access article distributed under the terms of the Creative Commons Attribution License, which permits unrestricted use, distribution, and reproduction in any medium, provided the original author and source are credited. 
Citation: Hong SP (2016) Pitfalls in Assessing the Depth of Invasion in Colorectal Neoplasia. Int J Gastroenterol Disord Ther 3: 123. doi: http://dx.doi. org/10.15344/2393-8498/2016/123

Page 2 of 2

3. Saito Y, Uraoka T, Matsuda T, Emura F, Ikehara H, et al. (2007) Endoscopic treatment of large superficial colorectal tumors: a case series of 200 endoscopic submucosal dissections (with video). Gastrointest Endosc 66: 966-973.

4. Tamegai Y, Saito Y, Masaki N, Hinohara C, Oshima T, et al. (2007) Endoscopic submucosal dissection: a safe technique for colorectal tumors. Endoscopy 39: 418-422.

5. Kudo Se, Lambert R, Allen Jl, Fujii H, Fujii T, et al. (2008) Nonpolypoid neoplastic lesions of the colorectal mucosa. Gastrointest Endosc 68: S347.

6. Kitajima K, Fujimori T, Fujii S, Takeda J, Ohkura Y, et al. (2004) Correlations between lymph node metastasis and depth of submucosal invasion in submucosal invasive colorectal carcinoma: a Japanese collaborative study. J Gastroenterol 39: 534-543.

7. Utsumi T, Iwatate M1, Sano W1, Sunakawa H1, Hattori S1, et al. (2015) Polyp Detection, Characterization, and Management Using Narrow-Band Imaging with/without Magnification. Clin Endosc 48: 491-497.

8. Huang Y, Liu S, Gong W, Zhi F, Pan D, et al. (2009) Clinicopathologic features and endoscopic mucosal resection of laterally spreading tumors: experience from China. International journal of colorectal disease 24: 14411450.

9. Kim BC, Chang HJ, Han KS, Sohn DK, Hong CW, et al. (2011) Clinicopathological differences of laterally spreading tumors of the colorectum according to gross appearance. Endoscopy 43: 100-107.

10. Jang HW, Park SJ, Cheon JH, Kim TI, Kim WH, et al. (2014) Does magnifying narrow-band imaging or magnifying chromoendoscopy help experienced endoscopists assess invasion depth of large sessile and flat polyps? Dig Dis Sci 59: 1520-1528.

11. Park W, Kim B, Park SJ, Cheon JH, Kim TI, et al. (2014) Conventional endoscopic features are not sufficient to differentiate small, early colorectal cancer. World J Gastroenterol 20: 6586-6593.

12. Uno $Y$, Munakata A (1994) The non-lifting sign of invasive colon cancer. Gastrointest Endosc 40: 485-489.

13. Kanao H, Tanaka S, Oka S, Hirata M, Yoshida S, et al. (2009) Narrowband imaging magnification predicts the histology and invasion depth of colorectal tumors. Gastrointest Endosc 69: 631-636.

14. Sano Y, Ikematsu H, Fu KI, Emura F, Katagiri A, et al. (2009) Meshed capillary vessels by use of narrow-band imaging for differential diagnosis of small colorectal polyps. Gastrointest Endosc 69: 278-283.

15. Ikematsu H, Matsuda T, Emura F, Saito Y, Uraoka T, et al. (2010) Efficacy of capillary pattern type IIIA/IIIB by magnifying narrow band imaging for estimating depth of invasion of early colorectal neoplasms. BMC gastroenterology 10: 33 .

16. Hayashi N, Tanaka S, Hewett DG, Kaltenbach TR, Sano Y, et al. (2013) Endoscopic prediction of deep submucosal invasive carcinoma: validation of the narrow-band imaging international colorectal endoscopic (NICE) classification. Gastrointestinal endoscopy. 78: 625-632.

17. Kudo S, Rubio CA, Teixeira CR, Kashida H, Kogure E (2001) Pit pattern in colorectal neoplasia: endoscopic magnifying view. Endoscopy 33: 367373

18. Kudo S, Hirota S, Nakajima T, Hosobe S, Kusaka H, et al. (1994) Colorectal tumours and pit pattern. J Clin Pathol 47: 880-885 